\title{
Calcitonin-Induced Analgesia: An Unusual Hormone Specificity
}

\author{
Toshihiko MORIMOTO, Masaharu OKAMOTO and Masao KOIDA \\ Department of Pharmacology. Faculty of Pharmaceutical Sciences, \\ Nagasaki University, Nagasaki 852, Japan \\ Hiromichi NAKAMUTA* \\ Department of Pharmacology, Faculty of Pharmaceutical Sciences, \\ Setsunan University. Hirakata 573-01, Japan \\ Ronald C. ORLOWSKI \\ Armour Pharmaceutical Company, Kankakee, Illinois 60901, U.S.A. \\ Accepted September 17, 1984
}

Upon direct injection into the central nervous system of laboratory mammals, salmon calcitonin ( $\mathrm{SCT}$ ) is known to produce a variety of effects: antinociception (1), anorexia (2), and achlorhydria (3). Comparative studies $(4,5)$ on the anorectic potency of calcitonins of various animal origins have provided the results supporting the classical concept established for the hypocalcemic activity that the hormone of fish origin is biologically far more potent than the mammalian congeners (6).

However, it was recently noticed that in the dose which did develop complete anorexia in rats, $\mathrm{SCT}$ failed to induce antinociception, while porcine calcitonin ( $p C T)$ even in the same molar dose appeared to elicit antinociception (7). This is an unexpected observation from the above concept.

Wistar male rats weighing $250-350 \mathrm{~g}$ were used. SCT $(4500 \mathrm{U} / \mathrm{mg})$ was the synthetic product and $p C T(170 \mathrm{U} / \mathrm{mg})$ the natural one from the Armour Pharmaceutical Co. (Kankakee, IL, U.S.A.). Intracerebroventricular cannulation was done as described previously (4). The antinociceptive activity was evaluated by the method of Randall and Selitto (8). Baker's yeast $(20 \mathrm{w} / \mathrm{v} \%$ in saline, $0.10 \mathrm{ml} / \mathrm{rat}$ ) was injected into either one of the hindlimbs. Two hr later, peptide in vehicle $(0.1 \mathrm{M}$ ammonium acetate buffer, $\mathrm{pH}$ 4.7) or vehicle alone was administered intracerebroventricularly or subcutaneously.

\footnotetext{
* To whom reprint requests should be addressed.
}

The serum $\mathrm{Ca}$ level was estimated by the method of Gitelman (9).

As shown in Fig. 1, the anorectic dose of SCT $(0.062 \mathrm{nmol} / \mathrm{rat})$, which usually resulted in complete anorexia lasting about $24 \mathrm{hr}$, was unable to increase the response threshold. This dose of SCT is known to cause longlasting hypocalcemia, possibly by leaking into the systemic circulation and acting peripherally (10). In the doses tested, pCT did not induce either anorexia or hypocal. cemia, but elevated the response threshold to

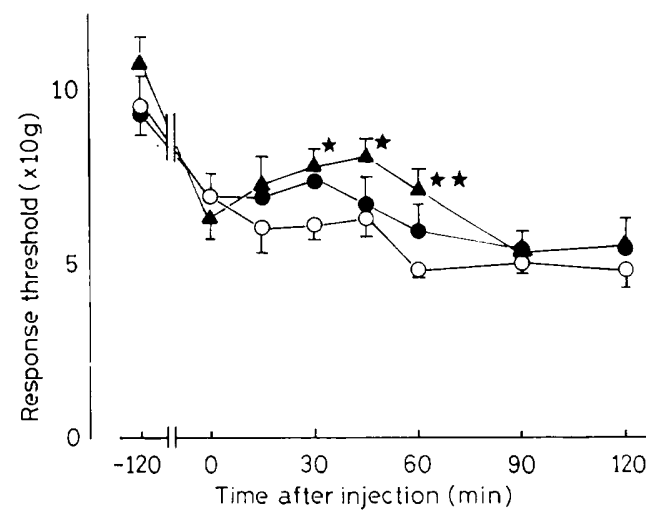

Fig. 1. Antinociception inducible by intracerebroventricular injection of calcitonirıs. At time 0 , vehicle $(10 \mu \mathrm{l} / \mathrm{rat}, \mathrm{O} \longrightarrow)$, sCT $(0.062 \mathrm{nmol} / \mathrm{rat}$, and $\mathrm{pCT}(0.062 \mathrm{nmol} / \mathrm{rat}, \boldsymbol{\Delta}-\mathbf{\Delta})$ were injected. Each point and bar represents the mean \pm S.E. (5-6 $\left.\mathrm{rats} / \mathrm{mear}_{1}\right)$, and the asterisk indicates a significant increase of the threshold (*: $\mathrm{P}<0.05$ and ${ }^{*}$ : $\mathrm{P}<$ 0.01 ). 


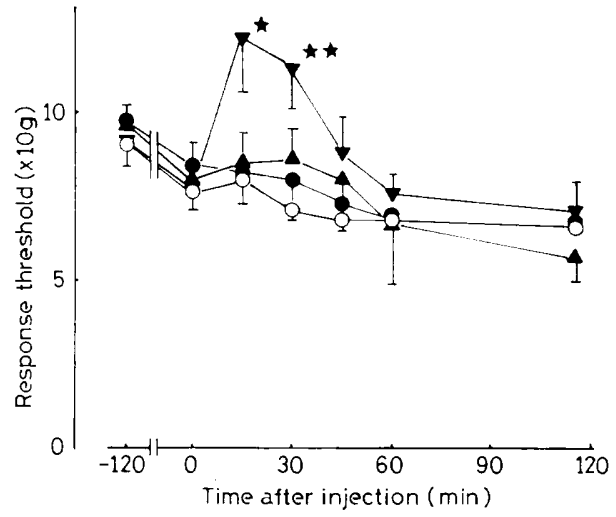

Fig. 2. Antinociception inducible by subcutaneous injection of calcitonins. At time 0 , vehicle $(1.0 \mathrm{ml} /$ $\mathrm{kg}, \mathrm{O}-\mathrm{O}), \mathrm{sCT}(1.6 \mathrm{nmol} / \mathrm{kg},-\mathrm{O})$, and $\mathrm{pCT}$ $(0.16 \mathrm{nmol} / \mathrm{kg}, \boldsymbol{\Lambda}-\boldsymbol{\Delta}$ and $1.6 \mathrm{nmol} / \mathrm{kg}, \boldsymbol{\nabla} \longrightarrow \boldsymbol{\nabla})$ were injected. Each point and bar represents the mean \pm S.E. (6-7 rats/mean), and the asterisk indicates a significant increase of the threshold $\left(^{*}: \mathrm{P}<\right.$ 0.05 and $^{* *}: \mathrm{P}<0.01$ ).

a small but significant extent.

Even when injected systemically, pCT was found to be active. Subcutaneous injection of $1.6 \mathrm{nmol} / \mathrm{kg}$ produced significant antinociception with a rapid onset and at least $30 \mathrm{~min}$ duration (Fig. 2). In contrast, sCT $(1.6 \mathrm{nmol} / \mathrm{kg})$ was again inactive in such a high dose level that decreased the serum $\mathrm{Ca}^{2+}$ level from $9.7 \mathrm{mg} / \mathrm{dl}$ to 8.6 at $1 \mathrm{hr}$ after injection.

The antinociceptive effect of pCT developed only on the limb into which yeast was injected. pCT has so far failed to increase the response threshold of the untreated hindlimb.

Though more detailed studies using other assay methods of antinociception are to be done, the results reported herein suggest that PCT even after central injection may exert its antinociceptive effect by acting on the peripheral site, and it is possible that the underlying mechanism is quite different from the ones conceptualized for the other actions of calcitonins $(11,12)$.

Acknowledgement: This work was supported in part by a Grant-in Aid for Scientific Research to M.K. (No. 58570931) from the Ministry of Education. Science and Culture, Japan, and also by financial aid to M.K. from Dr. Harumasa Toya of Sawai Pharmaceutical Co. (Osaka, Japarı).

\section{References}

1 Pecile, A., Ferri, S., Braga, P.C. and Olgiati, V.R.: Effect of intracerebroventricular calcitonin in the conscious rabbit. Experientia 31, 332-333 (1975)

2 Freed, W.J., Perlow, M.J. and Wyatt, R.J.: Calcitonin: inhibitory effect on eating in rats. Science 206, 850-852 (1979)

3 Morley, J.E., Levine, A.S. and Silvis, S.E.: Intraventricular calcitonin inhibits gastric acid secretion. Science 214, 671-673 (1981)

4 Yamamoto, Y., Nakamuta, H., Koida, M., Seyler, J.K. and Orlowski, R.C.: Calcitonin-induced anorexia in rats: a structure-activity study by intraventricular injections. Japan. J. Pharmacol. 32, 1013-1017 (1982)

5 Twery, M.J., Obie, J.F. and Cooper, C.W.: Ability of calcitonins to alter food and water consumption in the rat. Peptides (Fayetteville) 3, 749-755 (1982)

6 Copp, D.H.: Endocrine regulation of calcium metabolism. Annu. Rev. Physiol. 32, 61-86 (1970)

7 Koida, M., Okamoto, M., Morimoto, T. and Nakamuta, H.: Calcitonin-induced ana!gesia. Japan. J. Pharmacol. 36, Supp. 215P (1984)

8 Randall, L.O. and Selitto, J.J.: A method of measurement of analgesic activity on inflamed tissue. Arch. Int. Pharmacodyn. Ther. 3, 409419 (1957)

9 Gitelman, H.I.: An improved automated procedure for the determination of calcium in biological specimens. Anal. Biochem. 18, 521531 (1967)

10 Morimoto, T., Okamoto, M., Koida, M., Nakamuta, H., Stahl, G.L. and Orlowski, R.C.: Intracerebroventricular injection of $125 /$-salmon calcitonin in rats: Fate, anorexia and hypocalcemia. Japan. J. Pharmacol. 37 (1985) (in press)

11 Munson, P.L.: Physiology and pharmacology of thyrocalcitonin. In Handbook of Physiology, Edited by Greep, R.O. and Astwood, E.B., p. 443-464, Am. Physiol. Soc., Washington, D.C. (1976)

12 Koida, M., Yamamoto, Y., Nakamuta, H., Matsuo, J., Okamoto, M., Morimoto, T., Seyler, J.K. and Orlowski, R.C.: A novel effect of salmon calcitonin on in vitro Ca-uptake by rat brain hypothalamus: The regional and hormonal specificities. Japan. J. Pharmacol. 32, 981-986 (1982) 